\title{
Familial Pancreatic Cancer and Surveillance of High-Risk Individuals
}

\author{
Hiroyuki Matsubayashi, ${ }^{1,2}$, Kyoichi Takaori ${ }^{3}$, Chigusa Morizane ${ }^{4}$, and Yoshimi Kiyozumi ${ }^{1}$ \\ Divisions of ${ }^{1}$ Genetic Medicine Promotion and ${ }^{2}$ Endoscopy, Shizuoka Cancer Center, Shizuoka, ${ }^{3}$ Department of Surgery, Kyoto University \\ Graduate School of Medicine, Kyoto, and ${ }^{4}$ Division of Hepatobiliary and Pancreatic Oncology, National Cancer Center Hospital, Tokyo, Japan
}

Family history of pancreatic cancer (PC) is a risk factor for PC development, and the risk level correlates with the number of affected families. A case of PC with $\geq 1$ PC cases in the first-degree relative is broadly defined as familial pancreatic cancer (FPC) and accounts for $5 \%$ to $10 \%$ of total PC cases. FPC possesses several epidemiological, genetic and clinicopathological aspects that are distinct from those of conventional PCs. In Western countries, FPC registries have been established since the 1990s, and high-risk individuals are screened to detect early PCs. For the pharmacotherapy of FPC, especially in cases with germline pathogenic BRCA mutations, regimens using platinum and poly (ADP-ribose) polymerase inhibitor have recently been studied for their effectiveness. To date, the concept of FPC has prevailed in Western countries, and it has begun to infiltrate into Eastern countries. As the genetic background and environmental conditions vary in association with ethnicity and living area, we need to establish our own FPC registries and accumulate data in Asian countries. (Gut Liver 2019;13:498-505 )

Key Words: Familial pancreatic cancer; High risk; Genetic; Surveillance; Treatment

\section{INTRODUCTION}

Various human cancers show family history as a risk of the same cancer developing in related family members. ${ }^{1-3}$ Several case-control studies and cohort studies have demonstrated an increased risk of pancreatic cancer (PC) in those who have a first-degree relative (FDR) who is a PC patient (odds ratio [OR], $2.1^{4}$ to $5.3^{5}$; relative risk [RR], $1.5^{6}$ to $\left.1.7^{7}\right) .{ }^{8}$ The incidence of PC increases with the number of family members with PC (4.5-fold increased risk in a family with one case of PC, 6.4-fold in those with two FDRs, and 32-fold in those with $\geq 3$ FDRs). ${ }^{9}$ In a large sense, the presence of two or more PC patients within FDRs is defined as familial pancreatic cancer (FPC). ${ }^{10}$ In a narrow sense, known genetic syndromes are excluded from it; ${ }^{9}$ such as PeutzJeghers syndrome, ${ }^{11}$ hereditary pancreatitis, ${ }^{12}$ familial atypical multiple mole melanoma, ${ }^{13,14}$ hereditary breast-ovarian cancer (HBOC), ${ }^{15-17}$ Lynch syndrome, ${ }^{18,19}$ and familial adenomatous polyposis (Table 1). ${ }^{20}$ The incidence of FPC among total cases of PC is $5 \%$ to $10 \%$. We must bear in mind that "familial PC" is not a synonym for "inherited PC," and pathogenic germline mutation has been proven in only $<20 \%$ of FPC cases. ${ }^{21}$

\section{CHARACTERISTICS OF FPC}

\section{Epidemiology}

FPC has several epidemiological features that distinguish it from ordinary PC. Similar to other familial cancers, FPC shows a trend toward a younger onset (FPC age, 58 years $^{22}$ to 68 years ${ }^{23}$; compared to sporadic PC [SPC] age, 61 years $^{22}$ to 74 years $^{23}$ ) and an ethnic deviation (Ashkenazi Jewish >Caucasian). ${ }^{15}$ The lifetime risk of PC also increases with decreasing age of onset of PC in family members. ${ }^{23,24}$ Similar to sporadic cases, smoking, ${ }^{8,25}$ and diabetes ${ }^{8}$ are risks for FPC. Surprisingly, two European FPC registries $^{26-28}$ analyzed 106 FPC families through three generations and observed "anticipation" in the affected kindred of FPC patients; $;^{29}$ that is, a trend existed toward younger age and worse prognosis in the latest generation.

\section{Pathology and molecular biology (somatic)}

The pancreatic histology of FPC kindred often demonstrates multiple precancerous lesions, ${ }^{30}$ such as intraductal papillary mucinous neoplasm (IPMN) or pancreatic intraepithelial neoplasias (PanINs). ${ }^{31,32}$ Shi et al..$^{33}$ reported that these intraductal neoplasms were more frequently recognized in the FPC than in the SPC pancreas (2.8-fold, $\mathrm{p}<0.05)$. These lesions in FPC kindred

\footnotetext{
Correspondence to: Hiroyuki Matsubayashi

Division of Genetic Medicine Promotion and Endoscopy, Shizuoka Cancer Center, 1007, Shimonagakubo, Nagaizumi, Sunto-gun, Shizuoka 4118777, Japan

Tel: +81-55-989-5222, Fax: +81-55-989-5692, E-mail: h.matsubayashi@scchr.jp
}

Received on October 5, 2018. Revised on December 4, 2018. Accepted on December 13, 2018. Published online March 26, 2019 pISSN 1976-2283 eISSN 2005-1212 https://doi.org/10.5009/gnl18449

(a) This is an Open Access article distributed under the terms of the Creative Commons Attribution Non-Commercial License (http://creativecommons.org/licenses/by-nc/4.0) which permits unrestricted non-commercial use, distribution, and reproduction in any medium, provided the original work is properly cited. 
Table 1. Risk Level of Pancreatic Cancer in Individuals with Hereditary Cancer Syndromes

\begin{tabular}{|c|c|c|c|}
\hline Inherited syndrome & Causative gene & Relative risk & Cumulative risk $(\%)$ \\
\hline Peutz-Jeghers syndrome $^{11}$ & STK11 & 132 & $11-36$ \\
\hline Hereditary pancreatitis $^{12}$ & PRSS1 & $53-87$ & $40-55$ \\
\hline Familial atypical multiple mole melanoma ${ }^{13,14}$ & $\mathrm{CDKN} 2 \mathrm{~A} / \mathrm{p} 16$ & $13-22$ & 17 \\
\hline Hereditary breast-ovarian cancer syndrome $\mathrm{e}^{15-17}$ & BRCA1/2 & $4-13$ & $2-7$ \\
\hline Lynch syndrome $^{18,19}$ & MLH1, MSH2, MSH6, PMS2 & $5-9$ & 4 \\
\hline Familial adenomatous polyposis ${ }^{20}$ & APC, MUTYH & 5 & - \\
\hline
\end{tabular}

are associated with lobular parenchymal atrophy and chronic pancreatitis-like changes observable by endoscopic ultrasonography (EUS). ${ }^{32}$

Despite the difference in these precursor lesions, ${ }^{30,32}$ a blind histological observation of 519 FPCs and 561 SPCs by expert pathologists did not show significant difference in terms of tumor size, location, neural invasion, angiolymphatic invasion, lymph nodal metastasis, and pathological stage. ${ }^{34}$ The genomewide allelic status, ${ }^{35,36}$ and genetic (K-ras, TP53, and DPC4) and epigenetic (CDKN2A, NPTX2, ppENK, SPARC, etc.) alterations frequently observed in $\mathrm{PCs}^{37}$ were also similar between SPC and FPC.

\section{Genetics (germline)}

However, in a small proportion $(<20 \%)$ of FPC, deleterious germline mutation of the genes functioning in the homologous recombination (HR) pathway has been reported from the Western countries; ATM (mutation rate: $2 \%$ to $4 \%$ ), ${ }^{38}$ BRCA1 (0\% to 7\%), ${ }^{39,40}$ BRCA2 (4\% to $17 \%$ ), ${ }^{16,41}$ CHEK2 (1\% to 6\%), PALB2 (1\% to 3\%), ${ }^{43,44}$ and RAD51 (4\%). In Asian countries, Takai et $a l^{45}$ reported the similar mutation pattern in Japanese FPC cases (mutated in eight [15\%] of 54 analyzed FPC cases: BRCA2, three; PALB2, two; ATM, two; and MLH1, one). In Korea, although germline $B R C A 1 / 2$ mutation was recognized in $22 \%$ of the breast cancer patients with a family history of breast and ovarian cancers, ${ }^{46}$ null pathogenic BRCA2 mutation was detected in 60 PC patients. ${ }^{47}$ Even other than BRCA, defects of these genes cause dysfunction of the double strand DNA repair system (BRCAness). ${ }^{48}$

BRCA1/2 mutation carriers have a mild to moderate level of risk for PC (RRs, 2 to 8; lifetime risks, 2\% to 17\%), but some specific mutation types may have further increased risks. For instance, BRCA2 6174delT, which is a Jewish founder mutation, was detected in 13\% (3/23) of Jewish PC cases (odds for having $\mathrm{PC}, 12.8) .^{49}$ The BRCA2 K3326X mutation was detected in 5.6\% (5/144) of American FPC cases, significantly more frequently than in SPCs. ${ }^{50}$ A murine model confirmed that a germline BRCA2 mutation suffices to promote carcinogenesis by the KRAS mutation, ${ }^{51}$ which is recognized in nearly $90 \%$ of PC cases, ${ }^{52}$ explaining the function of BRCA2 mutation in FPC.

\section{CLINICAL MANAGEMENT OF FPC}

\section{Familial pancreatic cancer registry}

The FPC registry system began from the establishment of The National Familial Pancreas Tumor Registry (http://pathology. jhu.edu/pancreas/nfptr/history.php) (1994) at Johns Hopkins University (Baltimore, MD, USA). ${ }^{53}$ This was followed by the European Registry of Hereditary Pancreatitis and Familial Pancreas Cancer (https://www.lctu.org.uk/LCTU_NET/frontend/Default.as px?Data $=$ W1tiRzlqWVd4bF1dW09RPT1d) $(1997)^{26}$ at Liverpool University (Liverpool, UK) and the German National Case Collection for Familial Pancreatic Carcinoma (http://www.fapaca. de/) (1999) ${ }^{27}$ at Phillips University (Marburg, Germany). National FPC registries have also been established in Italy (2007), ${ }^{54}$ Spain (2009), ${ }^{55}$ Australia (2011), and Japan (Japanese Familial Pancreatic Cancer Registry, JFPCR; http://jfpcr.com) (2014). ${ }^{56}$ JFPCR aims prospective cohort study for FPCs and their relatives, basically to clarify the etiology of FPC and to research basic and clinical aspects of FPCs. At the initial organization, experts including clinicians, pathologists, basic researchers, statisticians, and genetic counselors from 20 nationwide nuclear hospitals gathered and formulated on the management system. Until the end of 2017, 66 families and 468 high risk individuals (HRIs) have been registered on the JFPCR.

\section{Surveillance of high-risk individuals}

Consortiums and symposiums have also been organized among several high volume centers and/or FPC registries across the globe, such as International Symposium on Inherited Diseases of the Pancreas (1997 $)^{57}$ and International Cancer of the Pancreas Screening Consortium (CAPS) (2011 ). ${ }^{58}$ Their aims have been to gather information on patients and families of PC and to study the cause of FPC, with the ultimate goal of improving the clinical practice of counseling and screening of the HRIs, and to devise early detection methods for PC and better treatments.

\section{1) Targeted pathological lesions}

The CAPS consortium summit held in Baltimore (2011) concluded that the success of a screening program for HRIs is defined as the detection and treatment of high-grade precursors 
$\left(\right.$ PanIN $^{31}$ and IPMN $\left.{ }^{59}\right)$-UICC-stage IA PC (T1NOM0; limited to the pancreas and no more than $2 \mathrm{~cm}$ in size). ${ }^{58}$ Today, the overall survival of UICC-stage IA cancer is unsatisfactory (5-year survival, 68.7\%). The ideal for a targeted lesion is thought as highgrade precursors-UICC-stage 0 PC (5-year survival, 85.8\%). ${ }^{60}$

\section{2) Screening candidates and lifestyle guidance at surveillance}

The risk level of the candidate individual is assessed based on the numbers of affected family members and hereditary syndromes (Table 1). The international consortiums recommended that an individual who had a 5 -fold risk ${ }^{58,61}$ to 10 -fold risk ${ }^{57}$ undergo PC screening. At present, the CAPS consortium has proposed nine conditions for candidate HRIs (Table 2), within a setting of greater than a 5-fold risk or a 5\% of lifetime risk of PC. ${ }^{58}$ A screening strategy should also evaluate the risk factors of lifestyle and pancreatic diseases, such as smoking, ${ }^{8,62}$ obesity, ${ }^{63,64}$ physical inactivity, ${ }^{64}$ diabetes, ${ }^{8,57,65}$ chronic pancreatitis, ${ }^{57,66,67}$ IPMN, ${ }^{59}$ pancreatic cyst, ${ }^{68}$ pancreatic duct ectasia, ${ }^{68}$ and so forth. For instance, a patient with diabetes mellitus and a smoking history and a patient with one FDR with PC each showed a 10fold risk when compared with negative controls. ${ }^{8}$ Therefore, the initial counseling should be used to present modifiable risks related to the lifestyle to HRIs and their improvement should be recommended; that is, smoking cessation, a healthy diet high in fruits and vegetables (vitamin), and regular exercise to control weight (body mass index $<25 \mathrm{~kg} / \mathrm{m}^{2}$ ).

\section{3) Modalities of screening}

Although not reaching complete consensus in the CAPS meeting, ${ }^{58}$ EUS is though as the most suitable modality, based on its ability to detect small pancreatic lesions $(<1 \mathrm{~cm}) .^{69,70}$ EUS is also superior at detecting risk findings frequently seen in HRIs, such as duct ectasia, cysts, ${ }^{68}$ and parenchymal findings of the pancreas. ${ }^{32}$ However, agreement is poor in terms of these characteristic findings, even among expert endosonographers. ${ }^{71}$ Drawbacks of EUS include the necessity for a relatively longtime fasting period and conscious sedation, operator-dependent visualization and interpretation, ${ }^{72}$ with a limited observation area in cases with a reconstructed upper gastrointestinal tract. In this sense, abdominal ultrasonography is a handy tool that may

Table 2. Candidates for Screening According to Consensus of the International Cancer of Pancreas Screening Consortium

Individuals with $\geq 3$ affected relatives, with $\geq 1$ affected FDR

Individuals with $\geq 2$ affected FDRs with $\mathrm{PC}$, with $\geq 1$ affected FDR

Individuals with $\geq 2$ affected relatives with $\mathrm{PC}$, with $\geq 1$ affected FDR

Peutz-Jeghers syndrome patients, regardless of family history of PC

Mutation carriers of CDKN2A, BRCA, PALB2 or mismatch

repair genes with 1 affected FDR

BRCA2 mutation carriers with 2 affected family members of PC

FDR, first-degree relative; PC, pancreatic cancer. substitute for EUS if the pancreas is well visualized without any blind spots ${ }^{68}$ for the Asian subjects with slim abdominal trunk. Magnetic resonance imaging (MRI) or magnetic resonance cholangiopancreatography (MRCP) is good at visualization of the pancreatic ductal systems. Dilation of the pancreatic duct and cyst formation are risk factors for $\mathrm{PC}^{68}$ and are actually frequently recognized in HRIs (cyst in 38.9\% and duct ectasia in 2.3\%), ${ }^{73}$ making MRCP a promising tool for assessing the risk level of HRIs.

EUS and MRI are considered the most accurate image tools with high agreement among the consortium experts (agreement: EUS 83.7\% and MRI/MRCP 73.5\%). ${ }^{58}$ EUS-guided fine needle aspiration and endoscopic retrograde cholangiopancreatography are applicable when abnormal findings or their changes are observed in other images. ${ }^{6974}$ In addition to image analysis, serum tumor markers, including carcinoembryonic antigen and carbohydrate antigen 19-9 should be checked each time..$^{58,74}$

\section{4) Timing to start screening and screening interval}

Screening in many institutions is started at 40 years of age ${ }^{69,75}$ or 10 years younger than the age of the youngest relative with PC. ${ }^{27,74}$ As PC develops in cases of Peutz-Jeghers syndrome at a young age (40.8 years), ${ }^{11}$ screening is started at 30 years old. ${ }^{69}$ However, detection of pancreatic lesions increases after age 50 to 60 years old. ${ }^{73}$ No consensus has been reached regarding the age to initiate screening and more than half (51\%) of the experts in CAPS consortium voted the initial screening at age 50 years old. ${ }^{58}$

Many institutions opt for yearly screening if the latest EUS and/or computed tomography is normal. ${ }^{58}$ Once an abnormal finding is observed, subsequent screening is done every 3 to 6 months ${ }^{28,69,76}$ or 3 to 12 months. ${ }^{58}$ The endorsed screening interval for a non-suspicious cyst is 6 to 12 months, 3 months for a newly detected solid lesion if surgery is not imminent, and 3 months for an indeterminate main pancreatic duct stricture. The natural history and progression of FPC still require study to determine the appropriate duration for screening intervals in relation to the risk level.

\section{5) Surgical indications and procedures}

The extent of resection is controversial, depending on the therapeutic concept. The choices are to remove all precancerous lesions ${ }^{74}$ or to resect only a targeted area that includes nodular or cystic lesions. ${ }^{69}$ In cases of HBOC with the BRCA mutation, risk-reducing salpingo-oophorectomy is affordable and has an acceptable level of complications. ${ }^{77}$ However, for the pancreas, total pancreatectomy (TP) has severe complications, including a considerable level of postsurgical in-hospital mortality (5\% to $23 \%$ in Germany) ${ }^{78,79}$ and subsequent serious glycemic control failure (mortality, $4 \%$ to $8 \%$ per year). ${ }^{80}$ A secondary pancreatectomy for the remnant pancreas can be conducted without increasing morbidity and mortality, ${ }^{81}$ so resection of the target 


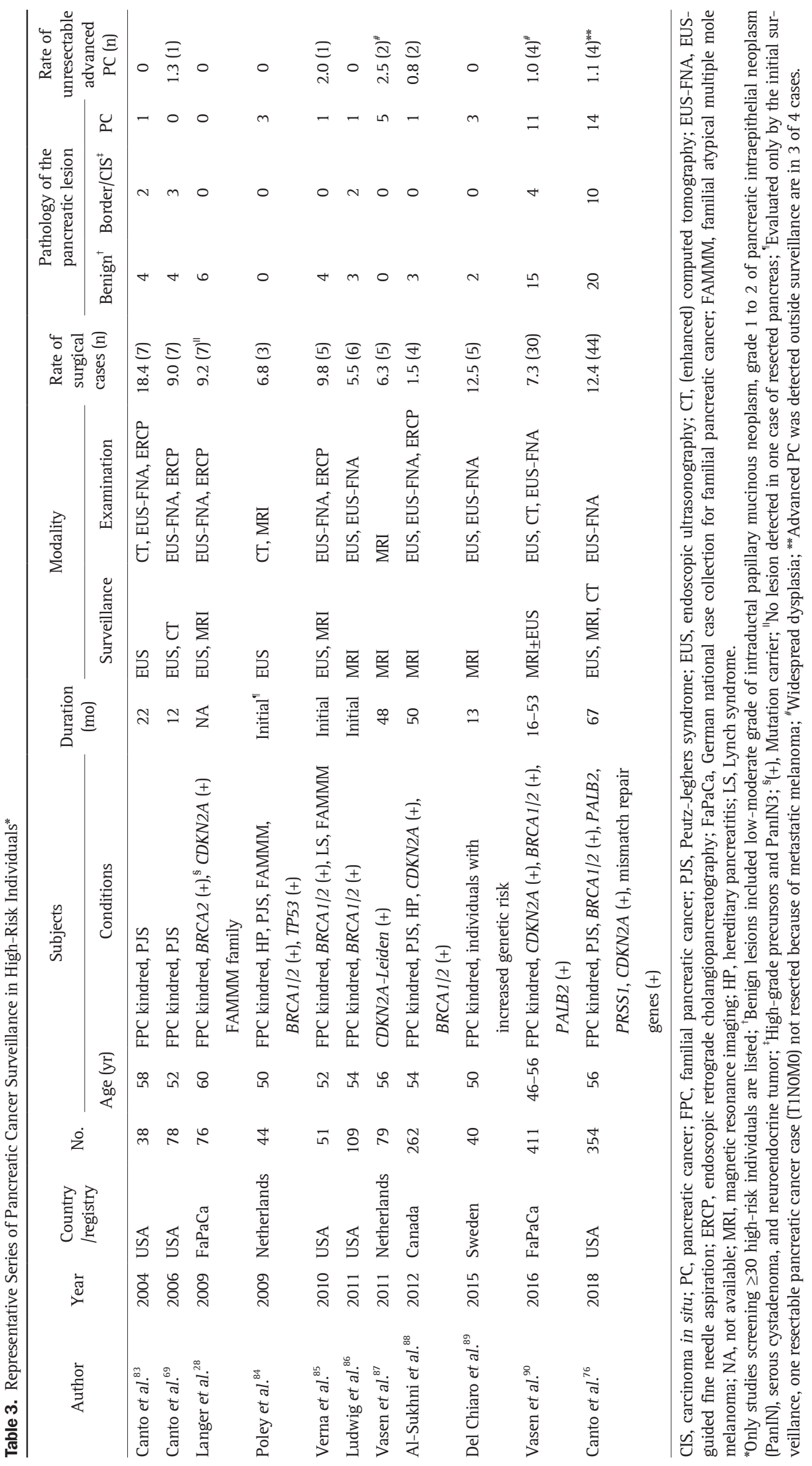


area, rather than TP, has been preferable thus far. However, most recently, due to the improvements in postsurgical quality of life, TP combined with islet autotransplantation have been considered and actually indicated for FPC kindred with premalignant lesions. ${ }^{80,82}$ Further improvements are expected in the future.

\section{6) Present outcome of surveillance}

Several surveillance results have been reported from the Western FPC registries (Table 3). ${ }^{21,28,69,76,83-90}$ About 2\% to $18 \%$ of the screened HRIs underwent surgery for suspected lesions. Roughly 30\% to 40\% of the resected cases were benign lesions that underwent unnecessary treatment, and only less than one fifth were borderline precursors and carcinoma in situ, or definitive targets of the surveillance. A small proportion of PC was resected at an early phase (T1NOM0), ${ }^{90}$ and some PC cases were detected at the advanced unresectable stage. These outcomes are still apart from the goal of the surveillance. However, a recent study from Johns Hopkins demonstrated that 3-year survival rate of $10 \mathrm{PC}$ cases diagnosed during surveillance was 85\% and was significantly longer than those detected outside the surveillance $(\mathrm{p}=0.0009)$. Also 10 cases with PanIN3 or high-grade IPMN were all alive after surgery (4.1 to 14.7 year). These data suggested that current surveillance system prolonged the PCassociated survival in HRIs. ${ }^{76}$

\section{CHEMOTHERAPY FOR FAMILIAL PANCREATIC CANCER WITH BRCA MUTATION}

For unresectable PC, on the basis of current evidence, FOLFIRINOX (fluorouracil, folic acid, irinotecan, and oxaliplatin) and gemcitabine-based regimens are standard choices of chemotherapy (median survival, 11 and 6-9 months, respectively). ${ }^{91}$ However, in agreement with the response observed in HBOC patients, ${ }^{92,93}$ PC patients with germline BRCA1/2 mutation carriers respond well to platinum-based chemotherapy. Golan et al..$^{94}$ retrospectively compared overall survival (OS) of 43 patients with stage III-IV PC with BRCA mutation carriers in terms of their chemotherapy regimen-either platinum or nonplatinum. Superior OS was observed for patients treated with platinum chemotherapy $(n=22)$ than with non-platinum $(n=21)$ (22 months vs 9 months; $p=0.039$ ). A similar effect was experimentally confirmed. PC xenografts harvested from BRCA mutation carriers and implanted into nude mice showed sensitivity to both gemcitabine and cisplatin, meanwhile, xenografts from BRCA wild cases demonstrated sensitivity only to gemcitabine. ${ }^{95}$ A joint study by Johns Hopkins University and the MD Anderson Cancer Center ${ }^{96}$ analyzed effectiveness of platinum-based chemotherapy in metastatic PC patients $(n=549)$ by familial cancer history, although BRCA status was not described, and demonstrated a superior OS in patients with family history of either breast, ovarian, or PC ( $\mathrm{p}=0.003)$. Survival was strongly associated with the number of relatives with BRCA-related malignancy $(\mathrm{p}=0.009)$. Kondo et al. ${ }^{97}$ analyzed on the somatic mutations of HR-related genes (written in above) in 30 PC cases and reported longer progression-free survival after initiation of oxaliplatin-based chemotherapy in HR-related gene mutant group than in wild-type group (20.8 months vs 1.7 months, $\mathrm{p}=0.049$ ).

Kaufman et al. ${ }^{93}$ reported that a PARP inhibitor (PARPi) treatment induced a $22 \%$ response ratio with 4.6 months of progression-free survival in BRCA-mutant PC patients who had already showed progression resistant to the gemcitabine treatment. PARPi may be effective not only for breast and ovarian cancers ${ }^{98}$ but also for PC cases with deficiency in the HR pathway; that is, as mentioned, in cases with either mutation of ATM, CHEK2, BRCA1, BRCA2, PALB2, or Rad51. This outcome is explained by a synthetic lethal theory, where apoptosis is induced by blocking both the single- and double-strand DNA break repair system. ${ }^{99}$ Currently, data are lacking with respect to PARPi use against FPC in causative mutation carriers and several phase II/III studies are now ongoing (https://clinicaltrials. gov). Future outcomes are expected.

\section{CONCLUSIONS}

Family history of PC and some genetic syndromes need to be taken into account when screening to detect early pancreatic cancer. So far, basic and clinical researches on the basis of family registries have accumulated much scientific information of FPC in the Western countries. However, at present, outcome of screening of HRIs is still not satisfactory. As life style, food, ethnicity, and medical system are different between the Western and Eastern countries, to detect early PC, we need to establish our own FPC registries and surveillance programs in the Asian countries.

\section{CONFLICTS OF INTEREST}

No potential conflict of interest relevant to this article was reported.

\section{ACKNOWLEDGEMENTS}

All authors are core members of Japanese Familial Pancreatic Cancer Study Group. H.M drafted, and all other authors reviewed and provided beneficial comments.

\section{ORCID}

Hiroyuki Matsubayashi https://orcid.org/0000-0002-7050-2351 


\section{REFERENCES}

1. Ait Ouakrim D, Lockett T, Boussioutas A, Hopper JL, Jenkins MA. Screening participation for people at increased risk of colorectal cancer due to family history: a systematic review and meta-analysis. Fam Cancer 2013;12:459-472.

2. Turati F, Edefonti V, Talamini R, et al. Family history of liver cancer and hepatocellular carcinoma. Hepatology 2012;55:14161425.

3. Win AK, Reece JC, Ryan S. Family history and risk of endometrial cancer: a systematic review and meta-analysis. Obstet Gynecol 2015;125:89-98.

4. Inoue M, Tajima K, Takezaki T, et al. Epidemiology of pancreatic cancer in Japan: a nested case-control study from the Hospitalbased Epidemiologic Research Program at Aichi Cancer Center (HERPACC). Int J Epidemiol 2003;32:257-262.

5. Falk RT, Pickle LW, Fontham ET, Correa P, Fraumeni JF Jr. Lifestyle risk factors for pancreatic cancer in Louisiana: a case-control study. Am J Epidemiol 1988;128:324-336.

6. Coughlin SS, Calle EE, Patel AV, Thun MJ. Predictors of pancreatic cancer mortality among a large cohort of United States adults. Cancer Causes Control 2000;11:915-923.

7. Hemminki K, Li X. Familial and second primary pancreatic cancers: a nationwide epidemiologic study from Sweden. Int J Cancer 2003;103:525-530

8. Matsubayashi H, Maeda A, Kanemoto H, et al. Risk factors of familial pancreatic cancer in Japan: current smoking and recent onset of diabetes. Pancreas 2011;40:974-978.

9. Klein AP, Brune KA, Petersen GM, et al. Prospective risk of pancreatic cancer in familial pancreatic cancer kindreds. Cancer Res 2004;64:2634-2638.

10. Petersen GM. Familial pancreatic cancer. Semin Oncol 2016:43:548-553.

11. Giardiello FM, Brensinger JD, Tersmette AC, et al. Very high risk of cancer in familial Peutz-Jeghers syndrome. Gastroenterology 2000;119:1447-1453.

12. Whitcomb DC, Applebaum S, Martin SP. Hereditary pancreatitis and pancreatic carcinoma. Ann N Y Acad Sci 1999;880:201-209.

13. Lynch HT, Fusaro RM, Lynch JF, Brand R. Pancreatic cancer and the FAMMM syndrome. Fam Cancer 2008;7:103-112.

14. Vasen HF, Gruis NA, Frants RR, van Der Velden PA, Hille ET, Bergman W. Risk of developing pancreatic cancer in families with familial atypical multiple mole melanoma associated with a specific 19 deletion of p16 (p16-Leiden). Int J Cancer 2000;87:809811

15. Lynch HT, Deters CA, Lynch JF, Brand RE. Familial pancreatic carcinoma in Jews. Fam Cancer 2004;3:233-240.

16. Murphy KM, Brune KA, Griffin C, et al. Evaluation of candidate genes MAP2K4, MADH4, ACVR1B, and BRCA2 in familial pancreatic cancer: deleterious BRCA2 mutations in 17\%. Cancer Res 2002;62:3789-3793.

17. Breast Cancer Linkage Consortium. Cancer risks in BRCA2 muta- tion carriers. J Natl Cancer Inst 1999:91:1310-1316.

18. Kastrinos F, Mukherjee B, Tayob N, et al. Risk of pancreatic cancer in families with Lynch syndrome. JAMA 2009;302:1790-1795.

19. Aarnio M, Sankila R, Pukkala E, et al. Cancer risk in mutation carriers of DNA-mismatch-repair genes. Int J Cancer 1999;81:214218.

20. Giardiello FM, Offerhaus GJ, Lee DH, et al. Increased risk of thyroid and pancreatic carcinoma in familial adenomatous polyposis. Gut 1993;34:1394-1396.

21. Matsubayashi H, Takaori K, Morizane C, et al. Familial pancreatic cancer: concept, management and issues. World J Gastroenterol 2017;23:935-948.

22. James TA, Gibbs JF. Pancreatic cancer screening: identifying premalignant disease. Future Oncol 2005;1:191-195.

23. Brune KA, Lau B, Palmisano E, et al. Importance of age of onset in pancreatic cancer kindreds. J Natl Cancer Inst 2010;102:119-126.

24. Del Chiaro M, Zerbi A, Falconi M, et al. Cancer risk among the relatives of patients with pancreatic ductal adenocarcinoma. Pancreatology 2007;7:459-469.

25. Yeo TP, Hruban RH, Brody J, Brune K, Fitzgerald S, Yeo CJ. Assessment of "gene-environment" interaction in cases of familial and sporadic pancreatic cancer. J Gastrointest Surg 2009;13:14871494.

26. Howes N, Lerch MM, Greenhalf W, et al. Clinical and genetic characteristics of hereditary pancreatitis in Europe. Clin Gastroenterol Hepatol 2004;2:252-261.

27. Schneider R, Slater EP, Sina M, et al. German national case collection for familial pancreatic cancer ( $\mathrm{FaPaCa})$ : ten years experience. Fam Cancer 2011;10:323-330.

28. Langer P, Kann PH, Fendrich V, et al. Five years of prospective screening of high-risk individuals from families with familial pancreatic cancer. Gut 2009;58:1410-1418.

29. McFaul CD, Greenhalf W, Earl J, et al. Anticipation in familial pancreatic cancer. Gut 2006;55:252-258.

30. Humphris JL, Johns AL, Simpson SH, et al. Clinical and pathologic features of familial pancreatic cancer. Cancer 2014;120:36693675.

31. Takaori K, Hruban RH, Maitra A, Tanigawa N. Pancreatic intraepithelial neoplasia. Pancreas 2004;28:257-262.

32. Brune K, Abe T, Canto M, et al. Multifocal neoplastic precursor lesions associated with lobular atrophy of the pancreas in patients having a strong family history of pancreatic cancer. Am J Surg Pathol 2006;30:1067-1076.

33. Shi C, Klein AP, Goggins M, et al. Increased prevalence of precursor lesions in familial pancreatic cancer patients. Clin Cancer Res 2009;15:7737-7743.

34. Singhi AD, Ishida H, Ali SZ, et al. A histomorphologic comparison of familial and sporadic pancreatic cancers. Pancreatology 2015;15:387-391

35. Abe T, Fukushima N, Brune K, et al. Genome-wide allelotypes of familial pancreatic adenocarcinomas and familial and sporadic intraductal papillary mucinous neoplasms. Clin Cancer Res 
2007;13:6019-6025.

36. Norris AL, Roberts NJ, Jones S, et al. Familial and sporadic pancreatic cancer share the same molecular pathogenesis. Fam Cancer 2015;14:95-103.

37. Brune K, Hong SM, Li A, et al. Genetic and epigenetic alterations of familial pancreatic cancers. Cancer Epidemiol Biomarkers Prev 2008;17:3536-3542.

38. Roberts NJ, Jiao Y, Yu J, et al. ATM mutations in patients with hereditary pancreatic cancer. Cancer Discov 2012;2:41-46.

39. Axilbund JE, Argani P, Kamiyama M, et al. Absence of germline BRCA1 mutations in familial pancreatic cancer patients. Cancer Biol Ther 2009;8:131-135.

40. Lynch HT, Deters CA, Snyder CL, et al. BRCA1 and pancreatic cancer: pedigree findings and their causal relationships. Cancer Genet Cytogenet 2005;158:119-125.

41. Goggins M, Schutte M, Lu J, et al. Germline BRCA2 gene mutations in patients with apparently sporadic pancreatic carcinomas. Cancer Res 1996;56:5360-5364.

42. Bartsch DK, Krysewski K, Sina-Frey M, et al. Low frequency of CHEK2 mutations in familial pancreatic cancer. Fam Cancer 2006;5:305-308.

43. Jones S, Hruban RH, Kamiyama M, et al. Exomic sequencing identifies PALB2 as a pancreatic cancer susceptibility gene. Science 2009;324:217.

44. Slater EP, Langer P, Niemczyk E, et al. PALB2 mutations in European familial pancreatic cancer families. Clin Genet 2010;78:490494.

45. Takai E, Yachida S, Shimizu K, et al. Germline mutations in Japanese familial pancreatic cancer patients. Oncotarget 2016;7:7422774235.

46. Kang E, Seong MW, Park SK, et al. The prevalence and spectrum of BRCA1 and BRCA2 mutations in Korean population: recent update of the Korean Hereditary Breast Cancer (KOHBRA) study. Breast Cancer Res Treat 2015;151:157-168.

47. Cho JH, Bang S, Park SW, Chung JB, Song SY. BRCA2 mutations as a universal risk factor for pancreatic cancer has a limited role in Korean ethnic group. Pancreas 2008;36:337-340.

48. Turner N, Tutt A, Ashworth A. Hallmarks of 'BRCAness' in sporadic cancers. Nat Rev Cancer 2004;4:814-819.

49. Figer A, Irmin L, Geva R, et al. The rate of the 6174delT founder Jewish mutation in BRCA2 in patients with non-colonic gastrointestinal tract tumours in Israel. Br J Cancer 2001;84:478-481.

50. Martin ST, Matsubayashi H, Rogers CD, et al. Increased prevalence of the BRCA2 polymorphic stop codon K3326X among individuals with familial pancreatic cancer. Oncogene 2005;24:3652-3656.

51. Skoulidis F, Cassidy LD, Pisupati V, et al. Germline Brca2 heterozygosity promotes Kras(G12D): driven carcinogenesis in a murine model of familial pancreatic cancer. Cancer Cell 2010;18:499-509.

52. Matsubayashi H, Watanabe H, Yamaguchi T, et al. Multiple K-ras mutations in hyperplasia and carcinoma in cases of human pancreatic carcinoma. Jpn J Cancer Res 1999;90:841-848.

53. Petersen GM, de Andrade M, Goggins M, et al. Pancreatic cancer genetic epidemiology consortium. Cancer Epidemiol Biomarkers Prev 2006;15:704-710.

54. Del Chiaro M, Zerbi A, Capurso G, et al. Familial pancreatic cancer in Italy. Risk assessment, screening programs and clinical approach: a position paper from the Italian Registry. Dig Liver Dis 2010;42:597-605.

55. Mocci E, Guillen-Ponce C, Earl J, et al. PanGen-Fam: Spanish registry of hereditary pancreatic cancer. Eur J Cancer 2015;51:19111917.

56. Wada K, Takaori K, Traverso LW, et al. Clinical importance of Familial Pancreatic Cancer Registry in Japan: a report from kick-off meeting at International Symposium on Pancreas Cancer 2012. J Hepatobiliary Pancreat Sci 2013;20:557-566.

57. Brand RE, Lerch MM, Rubinstein WS, et al. Advances in counselling and surveillance of patients at risk for pancreatic cancer. Gut 2007;56:1460-1469.

58. Canto MI, Harinck F, Hruban RH, et al. International Cancer of the Pancreas Screening (CAPS) Consortium summit on the management of patients with increased risk for familial pancreatic cancer. Gut 2013;62:339-347.

59. Tanaka M, Fernández-del Castillo C, Adsay V, et al. International consensus guidelines 2012 for the management of IPMN and MCN of the pancreas. Pancreatology 2012;12:183-197.

60. Egawa S, Toma H, Ohigashi H, et al. Japan Pancreatic Cancer Registry; 30th year anniversary: Japan Pancreas Society. Pancreas 2012;41:985-992.

61. Sud A, Wham D, Catalano M, Guda NM. Promising outcomes of screening for pancreatic cancer by genetic testing and endoscopic ultrasound. Pancreas 2014;43:458-461.

62. Lynch SM, Vrieling A, Lubin JH, et al. Cigarette smoking and pancreatic cancer: a pooled analysis from the pancreatic cancer cohort consortium. Am J Epidemiol 2009;170:403-413.

63. Larsson SC, Orsini N, Wolk A. Body mass index and pancreatic cancer risk: a meta-analysis of prospective studies. Int J Cancer 2007;120:1993-1998.

64. Stolzenberg-Solomon RZ, Adams K, Leitzmann M, et al. Adiposity, physical activity, and pancreatic cancer in the National Institutes of Health-AARP Diet and Health Cohort. Am J Epidemiol 2008;167:586-597.

65. Huxley R, Ansary-Moghaddam A, Berrington de González A, Barzi F, Woodward M. Type-II diabetes and pancreatic cancer: a meta-analysis of 36 studies. Br J Cancer 2005;92:2076-2083.

66. Lowenfels AB, Maisonneuve P, Cavallini G, et al. Pancreatitis and the risk of pancreatic cancer. International Pancreatitis Study Group. N Engl J Med 1993;328:1433-1437.

67. Talamini G, Falconi M, Bassi C, et al. Incidence of cancer in the course of chronic pancreatitis. Am J Gastroenterol 1999;94:12531260.

68. Tanaka S, Nakao M, Ioka T, et al. Slight dilatation of the main pancreatic duct and presence of pancreatic cysts as predictive signs of pancreatic cancer: a prospective study. Radiology 2010;254:965-972 
69. Canto MI, Goggins M, Hruban RH, et al. Screening for early pancreatic neoplasia in high-risk individuals: a prospective controlled study. Clin Gastroenterol Hepatol 2006;4:766-781.

70. Yasuda I, Iwashita T, Doi S, Nakashima M, Moriwaki H. Role of EUS in the early detection of small pancreatic cancer. Dig Endosc 2011;23 Suppl 1:22-25.

71. Topazian M, Enders F, Kimmey M, et al. Interobserver agreement for EUS findings in familial pancreatic-cancer kindreds. Gastrointest Endosc 2007;66:62-67.

72. Eisen GM, Dominitz JA, Faigel D0, et al. Guidelines for credentialing and granting privileges for endoscopic ultrasound. Gastrointest Endosc 2001;54:811-814.

73. Canto MI, Hruban RH, Fishman EK, et al. Frequent detection of pancreatic lesions in asymptomatic high-risk individuals. Gastroenterology 2012;142:796-804.

74. Brentnall TA, Bronner MP, Byrd DR, Haggitt RC, Kimmey MB. Early diagnosis and treatment of pancreatic dysplasia in patients with a family history of pancreatic cancer. Ann Intern Med 1999;131:247-255.

75. Mucci LA, Hjelmborg JB, Harris JR, et al. Familial risk and heritability of cancer among twins in Nordic countries. JAMA 2016;315:68-76.

76. Canto MI, Almario JA, Schulick RD, et al. Risk of neoplastic progression in individuals at high risk for pancreatic cancer undergoing long-term surveillance. Gastroenterology 2018;155:740751.

77. Kauff ND, Barakat RR. Risk-reducing salpingo-oophorectomy in patients with germline mutations in BRCA1 or BRCA2. J Clin Oncol 2007;25:2921-2927.

78. Nimptsch U, Krautz C, Weber GF, Mansky T, Grützmann R. Nationwide in-hospital mortality following pancreatic surgery in Germany is higher than anticipated. Ann Surg 2016;264:10821090.

79. Müller MW, Friess $\mathrm{H}$, Kleeff $\mathrm{J}$, et al. Is there still a role for total pancreatectomy? Ann Surg 2007;246:966-974

80. Mehrabi A, Golriz M, Adili-Aghdam F, et al. Expanding the indications of pancreas transplantation alone. Pancreas 2014;43:11901193.

81. Miyazaki M, Yoshitomi H, Shimizu H, et al. Repeat pancreatectomy for pancreatic ductal cancer recurrence in the remnant pancreas after initial pancreatectomy: is it worthwhile? Surgery 2014;155:58-66.

82. Heidt DG, Burant C, Simeone DM. Total pancreatectomy: indications, operative technique, and postoperative sequelae. J Gastrointest Surg 2007;11:209-216.

83. Canto MI, Goggins M, Yeo CJ, et al. Screening for pancreatic neoplasia in high-risk individuals: an EUS-based approach. Clin Gastroenterol Hepatol 2004;2:606-621.

84. Poley JW, Kluijt I, Gouma DJ, et al. The yield of first-time endoscopic ultrasonography in screening individuals at a high risk of developing pancreatic cancer. Am J Gastroenterol 2009;104:2175-
2181.

85. Verna EC, Hwang C, Stevens PD, et al. Pancreatic cancer screening in a prospective cohort of high-risk patients: a comprehensive strategy of imaging and genetics. Clin Cancer Res 2010;16:50285037.

86. Ludwig E, Olson SH, Bayuga S, et al. Feasibility and yield of screening in relatives from familial pancreatic cancer families. Am J Gastroenterol 2011;106:946-954.

87. Vasen HF, Wasser M, van Mil A, et al. Magnetic resonance imaging surveillance detects early-stage pancreatic cancer in carriers of a p16-Leiden mutation. Gastroenterology 2011;140:850-856.

88. Al-Sukhni W, Borgida A, Rothenmund H, et al. Screening for pancreatic cancer in a high-risk cohort: an eight-year experience. J Gastrointest Surg 2012;16:771-783.

89. Del Chiaro M, Verbeke CS, Kartalis N, et al. Short-term results of a magnetic resonance imaging-based swedish screening program for individuals at risk for pancreatic cancer. JAMA Surg 2015;150:512-518.

90. Vasen H, Ibrahim I, Ponce CG, et al. Benefit of surveillance for pancreatic cancer in high-risk individuals: outcome of long-term prospective follow-up studies from three European expert centers. J Clin Oncol 2016;34:2010-2019.

91. Kamisawa T, Wood LD, Itoi T, Takaori K. Pancreatic cancer. Lancet 2016;388:73-85.

92. Alsop K, Fereday S, Meldrum C, et al. BRCA mutation frequency and patterns of treatment response in BRCA mutation-positive women with ovarian cancer: a report from the Australian Ovarian Cancer Study Group. J Clin Oncol 2012;30:2654-2663.

93. Kaufman B, Shapira-Frommer R, Schmutzler RK, et al. Olaparib monotherapy in patients with advanced cancer and a germline BRCA1/2 mutation. J Clin Oncol 2015;33:244-250.

94. Golan T, Kanji ZS, Epelbaum R, et al. Overall survival and clinical characteristics of pancreatic cancer in BRCA mutation carriers. Br J Cancer 2014;111:1132-1138.

95. Lohse I, Borgida A, Cao P, et al. BRCA1 and BRCA2 mutations sensitize to chemotherapy in patient-derived pancreatic cancer xenografts. Br J Cancer 2015;113:425-432.

96. Fogelman D, Sugar EA, Oliver G, et al. Family history as a marker of platinum sensitivity in pancreatic adenocarcinoma. Cancer Chemother Pharmacol 2015;76:489-498.

97. Kondo T, Kanai M, Kou T, et al. Association between homologous recombination repair gene mutations and response to oxaliplatin in pancreatic cancer. Oncotarget 2018;9:19817-19825.

98. O’Sullivan CC, Moon DH, Kohn EC, Lee JM. Beyond breast and ovarian cancers: PARP inhibitors for BRCA mutation-associated and BRCA-like solid tumors. Front Oncol 2014;4:42.

99. Ashworth A. A synthetic lethal therapeutic approach: poly(ADP) ribose polymerase inhibitors for the treatment of cancers deficient in DNA double-strand break repair. J Clin Oncol 2008;26:37853790. 